\title{
Construction and characterization of porcine single-chain fragment variable antibodies that neutralize transmissible gastroenteritis virus in vitro
}

\author{
Fanqing Zhang ${ }^{1}$ Yuxue Chen ${ }^{1,2} \cdot$ Liang Yang ${ }^{1,2} \cdot$ Jianguo Zhu ${ }^{1,3}$
}

Received: 9 September 2018 / Accepted: 2 January 2019 / Published online: 7 February 2019

(c) Springer-Verlag GmbH Austria, part of Springer Nature 2019

\begin{abstract}
Transmissible gastroenteritis virus (TGEV) infection causes severe diarrhea in piglets and imposes a significant economic burden on pig farms. Single-chain fragment variable (scFv) antibodies effectively inhibit virus infection and could be a potential therapeutic reagent for preventing disease. In this study, a recombinant $\mathrm{scFv}$ antibody phage display library was constructed from peripheral blood lymphocytes of piglets infected with TGEV. The library was screened with four rounds of biopanning using purified TGEV antigen, and scFv antibodies that bound to TGEV were obtained. The scFv gene was subcloned into the pET-28a(+), and the constituted plasmid was introduced into Escherichia coli BL21 (DE3) for protein expression. All three scFv clones identified had neutralizing activity against TGEV. An immunofluorescence assay and western blot analysis demonstrated that two scFv antibodies reacted with the spike protein of TGEV. These results indicate that $\mathrm{scFv}$ antibodies provide protection against viral infection in vitro and may be a therapeutic candidate for both prevention and treatment of TGEV infection in swine.
\end{abstract}

\section{Introduction}

Transmissible gastroenteritis virus (TGEV) belongs to the genus Alphacoronavirus in the family Coronaviridae of the order Nidovirales [1]. It is an etiological agent of transmissible gastroenteritis (TGE), which causes watery diarrhea, dehydration and vomiting in pigs. Notably, neonatal piglets have a mortality rate of up to $100 \%$ following infection by TGEV [2,3]. TGEV infection often results in significant economic losses for pig farms.

Handling Editor: Diego G. Diel.

Jianguo Zhu

zhu_jg@sjtu.edu.cn

1 Key Laboratory of Urban Agriculture (South), Ministry of Agriculture, School of Agriculture and Biology, Shanghai JiaoTong University, Shanghai 200240, People's Republic of China

2 Shanghai Frontan Animal Health Co., Ltd., Shanghai 201502, People's Republic of China

3 School of Agriculture and Biology, Shanghai Key Lab of Veterinary Biology, Shanghai JiaoTong university, Shanghai 200240, People's Republic of China
The TGEV genome is composed of positive-stranded RNA that is $\sim 28.5 \mathrm{~kb}$ in length and encodes four major structural proteins: the spike $(\mathrm{S})$ protein, the membrane $(\mathrm{M})$ protein, the minor envelope (E) protein, and the nucleocapsid $(\mathrm{N})$ protein $[4,5]$. Among these, the surface protein $\mathrm{S}$, which is also an integral membrane protein, is the major inducer of neutralizing antibodies in a host. It mediates the attachment of viral particles to host cells via binding to the cellular receptor porcine aminopeptidase $\mathrm{N}$ (pAPN) before cell invasion [6, 7]. Consequently, the $S$ protein could be an excellent target for therapeutics that can block viral entry or vaccines that induce protective immunity against TGEV [8]. The TGEV S protein is artificially divided into the $\mathrm{S} 1$ domain (residues 1-790) and S2 domain (residues 790-1, 383) $[8,9]$. The $\mathrm{S} 1$ domain contains several neutralization epitopes, and four major antigenic sites (in the order C, B, $\mathrm{D}, \mathrm{A})$ are located in the $\mathrm{S} 1$ protein $[10,11]$.

Passive immunization with antibodies is a particularly effective method for protecting newborn piglets against TGEV infection, which can be achieved by immunizing pregnant sows with inactivated or attenuated vaccines [12]. Consequently, antibodies are produced in the colostrum or milk and newborn piglets are passively protected from TGEV when they suckle immune dams (via lactogenic immunity) [13, 14]. Previous studies have demonstrated 
that neonatal piglets that receive high titers of TGEV-specific antibodies in colostrum and milk are protected from TGEV-induced diarrhea $[15,16]$. Therefore, oral antibody administration may represent an alternative strategy for the prevention and treatment of TGEV infection.

Genetically engineered recombinant antibody fragments are increasingly used in medical therapy of many diseases, such as enteric colibacillosis, influenza, and Glässer's disease [17-21]. Single-chain fragment variable (scFv) antibodies constitute one of the most commonly used types of genetically engineered antibodies for treatment of disease $[22,23]$. The scFv antibody is a small engineered antibody (26-28 kDa) that includes a variable heavy $(\mathrm{VH})$ chain and variable light $(\mathrm{VL})$ chain linked by a flexible peptide linker. Compared with intact $\mathrm{IgG}$ molecules, $\mathrm{scFv}$ antibodies retain their antigen-binding capability despite removal of the constant regions and are genetically modified to increase affinity and specificity [24]. Moreover, $\mathrm{scFv}$ antibodies are easily expressed in a functional form in Escherichia coli [25]. scFv antibodies can neutralize various viruses, inhibit viral infection and protect hosts from infectious disease [26-28]. These studies indicate that $\mathrm{scFv}$ antibodies could act as a protective therapeutic treatment for virus infection.

In this study, a porcine antibody phage library was constructed from peripheral blood lymphocytes of TGEVinfected piglets. $\mathrm{scFv}$ antibodies that bound to TGEV were screened using the phage display method, and their TGEV neutralization capacity and specificity were determined. We identified and characterize porcine $\mathrm{scFv}$ antibodies that neutralize TGEV in vitro, and these might be promising therapeutic reagents for use in the prevention and treatment of porcine viral gastroenteritis.

\section{Materials and methods}

\section{Cells, viruses, plasmids and antibodies}

Swine testicle (ST) cells were purchased from Wuhan Boster Biological Technology Co. Ltd. The cells were routinely cultured in Dulbecco's modified Eagle medium (DMEM) (Invitrogen, Carlsbad, CA, USA), supplemented with 10\% fetal bovine serum (FBS) (Gibco, Grand Island, NY, USA), and incubated in a humidified atmosphere containing $5 \%$ $\mathrm{CO}_{2}$ at $37^{\circ} \mathrm{C}$. 293T cells (CRL-3216) were purchased from the American Type Culture Collection (ATCC, Manassas, VA, USA) and grown in DMEM supplemented with $10 \%$ FBS and $2 \mathrm{mM}$ L-glutamine in a humidified atmosphere containing $5 \% \mathrm{CO}_{2}$ at $37{ }^{\circ} \mathrm{C}$.

The swine transmissible gastroenteritis virus (TGEV, China strain, SHXB) (GenBank accession no. KP202848.1) stock was purchased from the Jiangsu Academy of Agricultural Sciences (JAAS) and propagated in ST cells.
The plasmid $\mathrm{p} 3 \times$ FLAG-TGEV-S was constructed in our laboratory using common cloning techniques. The nucleotide sequence of the $\mathrm{S}$ gene from the TGEV SHXB strain was amplified using a pair of primers: (i) SF (GGGGGCT AGCCCATGAAAAAACTATTTG; Nhe I site underlined) and (ii) SR (CCCCGAATTCGTTTGTCTAATAA; Xho I site underlined). PCR products were inserted into the p3 $\times$ FLAG-CMV-14 plasmid (Sigma-Aldrich, St. Louis, MO, USA) and $\mathrm{p} 3 \times$ FLAG-TGEV-S was generated.

Horseradish peroxidase (HRP)-conjugated anti-M13 antibody (Abcam, Cambridge, MA, USA), HRP-conjugated anti-His Tag antibody (Abcam), fluorescein isothiocyanate (FITC)-conjugated anti-His-tag antibody (Abcam), HRP-conjugated goat anti-mouse IgG (Beyotime Biotech, Shanghai, China), FITC-conjugated goat anti-mouse IgG (Beyotime Biotech), and HRP-conjugated goat anti-pig IgG (Jackson ImmunoResearch, West Grove, PA, USA) were used in this study. Mouse anti-TGEV S monoclonal antibody 3D11 was kindly provided by associate Prof. Zhibiao Yang and stored at our laboratory. TGEV-negative serum was collected from a 1-month-old piglet uninfected with TGEV.

\section{Preparation of TGEV antigen}

Confluent monolayers of ST cells were infected with TGEV strain SHXB at a multiplicity of infection (MOI) of 0.01 . After incubation for $1 \mathrm{~h}$ at $37^{\circ} \mathrm{C}$ in DMEM without FBS, complete medium was added. When the cytopathic effect reached $80 \%$, the culture fluids were harvested by centrifugation at $5,000 \times g$ for $10 \mathrm{~min}$. Viruses were purified using sucrose density gradient centrifugation as described previously and stored at $-80{ }^{\circ} \mathrm{C}$ until use [29].

\section{Phage library construction}

A total of 10 TGEV serum-negative piglets (large white) were purchased from a local breeding farm after birth. Each piglet was fed with commercial sterile milk and water. Piglets grown to fourteen days old were infected orally with $1 \times$ $10^{5} \mathrm{PFU}$ of TGEV. All piglets developed diarrhea, lethargy, dehydration and weight loss. No mortality was observed, and these animals recovered beginning at 10 days postinfection. At four weeks postinfection, piglets were inoculated orally with $1 \times 10^{7} \mathrm{PFU}$ of TGEV, and none of the piglets developed diarrhea after challenge. Four $\mathrm{mL}$ of blood was collected from each piglet at two weeks after the second infection and used to isolate peripheral blood lymphocytes (PBL) using lymphocyte separation reagents (Beyotime). Total RNA was extracted from the PBLs using TRIzol Reagent (Invitrogen) and reverse transcribed to cDNA using a reverse transcription kit (Takara, Qingdao, China).

Heavy-chain variable region $(\mathrm{VH})$ primers were designed to imitate the porcine VH gene sequence from the IMGT 
database (http://www.imgt.org). The light-chain variable region kappa (VLא) primer and light-chain variable region lambda (VL $\lambda$ ) primer were designed using data from the GenBank database (accession no. AF334738-AF334742 and accession no. NM_001243319, respectively). The VH and VL sequences were amplified using the cDNA as template and combined with a DNA sequence encoding a $\left(\mathrm{Gly}_{4} \mathrm{Ser}\right)_{3}$ peptide linker to form scFv fragments in an overlap PCR that was described by Wang et al. [30]. The primer sequences are listed in Table 1.

The scFv fragments were ligated into phagemid pCANTAB5e (Biovector Inc., Beijing, China), and the resultant recombinant DNA was used to transform Escherichia coli strain TG1 (Biovector) by electroporation. A portion of the transformed cells was plated onto an agar medium containing ampicillin $(100 \mu \mathrm{g} / \mathrm{mL})$ and $2 \%$ glucose, and library sizes were estimated by counting the colonies on the plates. The remaining culture was infected with $\mathrm{M} 13 \mathrm{KO} 7$ helper phage (Biovector). After overnight cultivation, the rescued phages were precipitated by addition of PEG/NaCl $(20 \%$ PEG 8000 and $15 \% \mathrm{NaCl}$ ). The precipitates were collected by centrifugation at $8000 \times g$ for $15 \mathrm{~min}$, suspended in phosphate-buffered saline (PBS), and used for biopanning.

\section{Biopanning of the antibody phage library}

The scFv antibody phage library was subjected to four rounds of biopanning against TGEV, as described in the standard protocol [31]. In the first round, a 96-well ELISA plate (Santa Cruz Biotech, Dallas, TX, USA) was coated with TGEV $(20 \mu \mathrm{g} / \mathrm{mL})$ at $4{ }^{\circ} \mathrm{C}$ overnight and blocked with $5 \%$ skimmed milk in PBS. Recombinant phages were added and incubated at $37^{\circ} \mathrm{C}$ for $2 \mathrm{~h}$ and the plate was then washed with PBST (PBS containing $0.05 \%$ Tween-20) to remove unbound phages. Bound phages were eluted from the plates with $100 \mu \mathrm{L}$ of $0.1 \mathrm{M}$ glycine- $\mathrm{HCl}(\mathrm{pH} 2.2)$, followed by neutralization with $50 \mu \mathrm{L}$ of $1 \mathrm{M}$ Tris- $\mathrm{HCl}$ (pH 8.8). Eluted phages were then used to infect $E$. coli TG1 and rescued by M13KO7 helper phage, and the generated phages were used for the next round of panning.

To select $\mathrm{scFv}$ antibodies with high affinity and specificity, the antigen concentration used was reduced to $10 \mu \mathrm{g} / \mathrm{mL}$, $5 \mu \mathrm{g} / \mathrm{mL}$ and $2 \mu \mathrm{g} / \mathrm{mL}$ in the following rounds of biopanning, and the number of washing steps was increased to 10,15 , and 20 times for stringent selection. Input and output phages for each round were quantified by counting the colonies on the plate, and the ratio of the output titer to the input titer was calculated.

\section{Phage ELISA}

Indirect ELISA was used to examine the phages that remained after several rounds of biopanning. TGEV antigens $(2 \mu \mathrm{g} / \mathrm{mL})$ as determined by checkerboard titration or ovalbumin $(10 \mu \mathrm{g} / \mathrm{mL})$ as a negative control in $0.1 \mathrm{M} \mathrm{NaHCO}_{3}$ (pH 8.6) was coated onto an ELISA plate and incubated at $4{ }^{\circ} \mathrm{C}$ overnight. Subsequently, wells were blocked with $5 \%$ skimmed milk in PBST for $2 \mathrm{~h}$, washed with PBS and then incubated with $50 \mu \mathrm{L}$ of phage solution in PBS at 37 ${ }^{\circ} \mathrm{C}$ for $2 \mathrm{~h}$. Polyclonal serum against TGEV obtained from experimentally infected piglets and an unrelated $\mathrm{scFv}, \mathrm{ZW}$ 88 , were used as positive and negative controls, respectively[32]. After washing the plate five times with PBST, a horseradish peroxidase (HRP)-conjugated anti-M13 antibody, HRP-conjugated anti-His monoclonal antibody, or HRP-conjugated anti-swine IgG (1:3000 dilution) was added to each well, and the mixture was incubated for $2 \mathrm{~h}$. The assays were detected by adding $100 \mu \mathrm{L}$ of 3,3',5,5'-tetramethylbenzidine (TMB) substrate to each well (Tiangen, Beijing, China) and stopped by adding $2 \mathrm{M} \mathrm{H}_{2} \mathrm{SO}_{4}$. The absorbance at $450 \mathrm{~nm}$ wavelength was measured using a plate reader (Biotek, Winooski, VT, USA).

Table 1 Primers used for the construction of the porcine antibody library

\begin{tabular}{|c|c|}
\hline Primer & Sequence $\left(5^{\prime}-3^{\prime}\right)$ \\
\hline VH-Back-linker & ATGGCCGAGGWGAAGCTGGTGGAGTCYGG \\
\hline VH-For-linker & GGATCCACCACCGCCCGAGCCACCGCCACCACGACGACTTCAACGCCTGG \\
\hline VLк1-Back-linker & GGCGGTGGTGGATCCGGTGGCGGCGGGTCTGCCATYGTGCTGACCCAGASTCC \\
\hline VLк2-Back-linker & GGCGGTGGTGGATCCGGTGGCGGCGGGTCTGAGACTCGTSATGACCCAGTCTCC \\
\hline VLк3-Back-linker & GGCGGTGGTGGATCCGGTGGCGGCGGGTCTGAGCTGCGTGATACACAGTCTCC \\
\hline VLк-For-linker & CGTTTGAKYTCCAGCTTGGTCCC \\
\hline VL $\lambda$-Back-linker & GGCGGTGGTGGATCCGGTGGCGGCGGGTCTCAGRCTGTGGTGACVCAGGAGCC \\
\hline VL $\lambda$-For-linker & ACCGAGGACGGTCAGCTGGGTGC \\
\hline VH-Backward $(S f i$ I) & 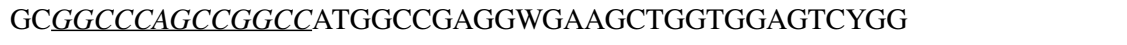 \\
\hline VLא-Forward(Not I) & TT $\underline{G C G G C C G C A C G T T T G A K Y T C C A G C T T G G T C C C}$ \\
\hline VLג-Forward(Not I) & TT $\underline{G C G G C C G C A C C G A G G A C G G T C A G C T G G G T G C}$ \\
\hline
\end{tabular}

The recognition sites for the restriction enzymes SfiI and NotI are underlined. The linker sequence is indicated in bold 


\section{scFv expression and purification}

The bound phage clones were selected for further analysis. The scFv fragments were ligated into the BamHI and XhoI sites of the pET-28a(+). The ligation mixture was transformed into BL21 (DE3) competent cells (Tiangen). For protein expression, transformed $E$. coli were grown in $200 \mathrm{~mL}$ of $2 \times$ YT medium containing $50 \mu \mathrm{g}$ of kanamycin per $\mathrm{mL}$ at $37^{\circ} \mathrm{C}$. When the optical density reached 0.6 at $600 \mathrm{~nm}$, $1.6 \mathrm{mM}$ isopropyl- $\beta$-D-thiogalactopyranoside (IPTG) was added to induce protein expression. The soluble scFv proteins were extracted from the bacteria and further purified using Ni-NTA agarose resin (Merck, Madison, WI, USA). The eluted products were quantified using a BCA protein assay kit (Thermo Scientific-Pierce, Rockford, IL, USA) and analyzed by $10 \%$ sodium dodecyl sulfate polyacrylamide gel electrophoresis (SDS-PAGE).

\section{Neutralization test}

To determine whether scFv antibodies showed neutralization activity against TGEV, a plaque-reduction neutralization (PRN) assay was performed as described by Hofmann and Wyler [33]. Briefly, $100 \mu \mathrm{L}$ of scFv antibody $(2 \mathrm{mg} / \mathrm{mL})$ was serially diluted twofold (1:20-1:2560) and pretreated with an equal volume of TGEV $\left(1000 \mathrm{TCID}_{50} / \mathrm{mL}\right)$ at $37^{\circ} \mathrm{C}$. Serum from an uninfected piglet and an unrelated scFv, ZW88, were used as negative controls. One hour later, the mixture was transferred to an ST cell monolayer in a 24-well plate and then incubated for another $1 \mathrm{~h}$. After washing with PBS, the cells were overlaid with $1 \%$ agar medium containing $0.5 \%$ TPCK-treated trypsin. When viral plaques became visible, the cells were fixed with $4 \%$ formaldehyde and stained with $0.5 \%$ crystal violet. The inhibition rate (in percent) for each $\mathrm{scFv}$ was calculated as follows: [1-(average number of plaques in the treated well/average number of plaques in the negative control scFv ZW 88 well)] $\times 100$. Each $\mathrm{scFv}$ was tested in triplicate.

\section{Immunofluorescence staining}

Selected scFv antibodies were screened for the binding of TGEV-infected cells. For this, ST cells were grown to 60 to $70 \%$ confluence on coverslips and infected with TGEV at an MOI of 0.01 for $24 \mathrm{~h}$. Cells were fixed in $4 \%$ paraformaldehyde and permeabilized with $0.5 \%$ Triton X-100 for 10 min. The cells were then incubated with $100 \mu \mathrm{L}$ of purified $\mathrm{scFv}$ antibody $(20 \mu \mathrm{g} / \mathrm{mL})$, and an unrelated $\mathrm{scFv}, \mathrm{ZW} 88$, was used as a negative-control antibody. The bound scFv antibodies were visualized using FITC-conjugated anti-Histag antibody (Abcam) and a Nikon Eclipse 80i fluorescence microscope. The 293 T cells transfected with $\mathrm{p} 3 \times$ FLAGTGEV-S were also analyzed by IFA using scFv antibody as the primary antibody at $48 \mathrm{~h}$ post-transfection.

\section{Western blot analysis}

ST cell lysates were harvested and lysed in RIPA lysis buffer (Beyotime). Equal amounts of protein were separated on SDS-PAGE gels and transferred to nitrocellulose filter membranes (Millipore, Billerica, MA, USA). Membranes were blocked with 5\% skimmed milk for $2 \mathrm{~h}$ at room temperature and incubated with primary antibodies (purified $\mathrm{scFv}$ antibody, unrelated scFv ZW 88, or TGEV-specific monoclonal antibody) and appropriate secondary antibodies (HRP-conjugated anti-His Tag antibody or HRP-conjugated goat antimouse IgG). Signals were detected using a SuperSignal West Pico Kit (Thermo Scientific, Inc., Waltham, MA, USA).

\section{Evaluation of the specificity of purified scFv by ELISA}

The specificity of the anti-TGEV scFv antibodies was determined using other porcine pathogens (see Table 2). Each well of a 96-well ELISA plate was coated with $100 \mu \mathrm{L}$ of a $2 \mu \mathrm{g} / \mathrm{mL}$ suspension of virus or bacteria $(\mathrm{n}=3)$, and purified soluble scFv antibodies were added to each well to evaluate their cross-reactivity with other pathogens. Wells coated with TGEV antigen were used as a positive control.
Table 2 Bacteria and viruses used in this study

\begin{tabular}{lll}
\hline Species & Strain & Source $^{\mathrm{a}}$ \\
\hline Transmissible gastroenteritis virus & SHXB & Jiangsu Academy of Agricultural Science \\
Porcine epidemic diarrhea virus & HLJBY & Northeast Agricultural University \\
Porcine respiratory syndrome virus & JXA1-R & Pulike Biological Engineering, INC. \\
Porcine circovirus type 2 & WG09 & Isolated strain \\
Enterotoxigenic Escherichia coli K88 & C83902 & CVCC \\
Enterotoxigenic Escherichia coli K99 & C83912 & CVCC \\
\hline
\end{tabular}

${ }^{\mathrm{a}} \mathrm{CVCC}=$ China Veterinary Culture Collection Center, Beijing, China 


\section{Statistical analysis}

Data are expressed as the mean \pm standard deviation (SD). Statistical analysis was performed using Student's $t$-test, whereby $p<0.01$ is considered to be statistically significant.

\section{Results}

\section{Construction of a phage library and selection of anti-TGEV scFv antibodies}

The lengths of VH-linker, VL-linker and scFv were approximately 390, 360 and 740 bp (Fig. 1A and B). Two porcine scFv phage libraries were constructed. The library size was
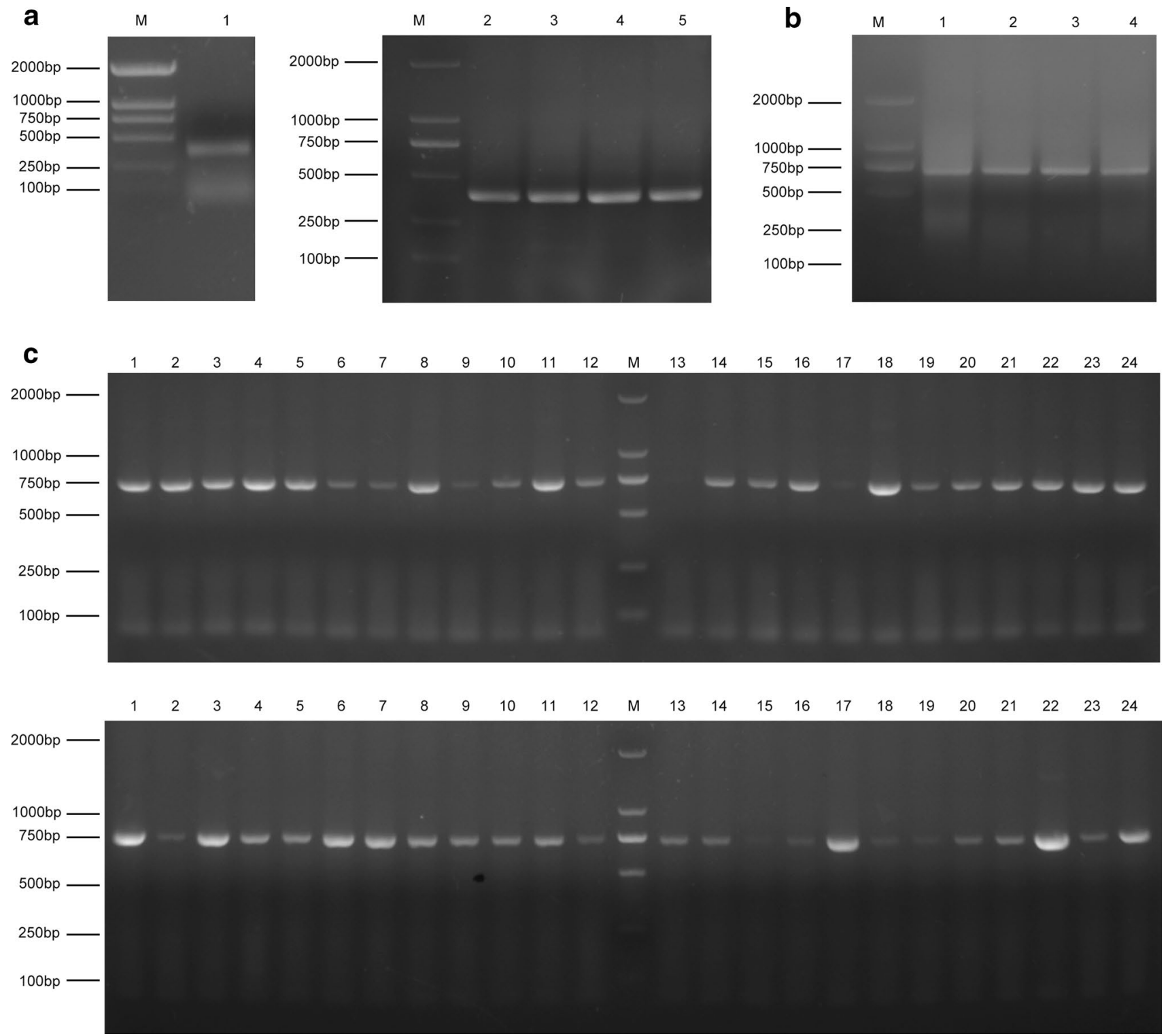

Fig. 1 Construction of the scFv antibody phage display library. (A) PCR amplification of VH-Linker and VL-Linker from cDNA of porcine peripheral blood lymphocytes. Lane M, 2000-bp DNA ladder marker (Takara); lane 1, VH-Linker fragments; lane 2, VLк1-Linker

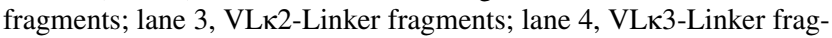
ments; lane 5, VL $\lambda$-Linker fragments. (B) Lane M, 2000-bp DNA ladder marker (Takara); lane 1, assembled $\mathrm{ScFv}$ genes containing

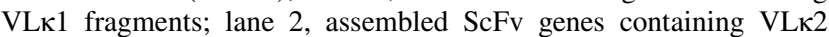

fragments; lane 3, assembled $\mathrm{scFv}$ genes containing VLк3 fragments; lane 4, assembled ScFv genes containing VL $\lambda$ fragments. (C) PCR amplification of $\mathrm{scFv}$ genes from the phage display library for assessing insertion frequency. Lane M, 2000-bp DNA ladder marker (Takara); lanes 1-24, scFv genes containing VLK fragments amplified by PCR; lanes $25-48$, scFv genes containing VL $\lambda$ fragments amplified by PCR 
$5.5 \times 10^{6} \mathrm{cfu} / \mathrm{mL}$ for $\mathrm{scFv}$ containing VLK and $7.2 \times 10^{6}$ $\mathrm{cfu} / \mathrm{mL}$ for $\mathrm{scFv}$ containing VL $\lambda$. Twenty-four clones were picked randomly from each library and subjected to PCR amplification in order to evaluate the efficiency of the library construction. The results showed that 23 out of 24 individual clones in the VLא library contained an insert of the expected size of scFv. All 24 of the clones in the VL $\lambda$ library contained an insert of the expected size of scFv (Fig. 1C). These results indicate that the porcine $\mathrm{scFv}$ libraries were successfully constructed.

The two porcine scFv antibody phage libraries (VL kappa library and VL lambda library) were mixed together, and the mixed library was used to screen $\mathrm{scFv}$ antibodies that bound to TGEV. In the first round of biopanning, the titer of the eluted phage was $5.75 \times 10^{4} \mathrm{cfu} / \mathrm{mL}$ (Table 3). Significant enrichment of the specific scFv phage antibody was observed after each round of biopanning, as indicated by the higher output/input ratio. In the fourth round of panning, the titer of output phage reached $10^{7} \mathrm{cfu} / \mathrm{mL}$, suggesting that specific bound phages were successfully enriched throughout the panning procedure.

In order to confirm the enrichment of TGEV-specific $\mathrm{scFv}$, the pooled amplified phage from the fourth round of panning was tested by phage ELISA. Forty-eight clones were randomly selected from the library and screened. Three clones with relatively high binding affinity were selected for further analysis $\left(\mathrm{OD}_{450}\right.$ value $>2.5$ times the negative control scFv ZW 88), and those were designated as TZZ 14, TZZ 19 and TZZ 43 (Fig. 2A). No TGEV binding was detected using the unrelated $\mathrm{scFv} \mathrm{ZW} 88$.

\section{Sequence analysis, expression and purification of selected scFv antibodies}

The amino acid sequences of the $\mathrm{scFv}$ antibodies are listed in Fig. 2B. Sequence analysis of the three clones confirmed that the $\mathrm{scFv} \mathrm{VH}$ gene fragments were connected with the VL gene fragments via a linker. The VH and VL domains each consisted of four framework regions (FRs) and three complementarity-determining regions (CDRs). The TZZ 14 contained a VL $\lambda$ chain, while TZZ 19 and TZZ 43 contained VL $\kappa$ chains. The amino acid sequences of the three scFv antibodies showed that the FRs were highly conserved and that amino acid sequences in the CDR3 regions of both heavy and light variable chains were diverse.

SDS-PAGE analysis showed that the scFv antibodies had a molecular weight of $\sim 30 \mathrm{kDa}$, were purified in a soluble form, and produced a single band (Fig. 2C). In western blot analysis, three $\mathrm{scFv}$ antibodies were recognized in the bacterial lysates by an anti-his monoclonal antibody and were absent in lysates of bacteria transformed with empty pET28a (+) (Fig. 2D).

\section{Neutralization test}

To determine whether scFv antibodies neutralized TGEV infection, a PRN assay was performed. An unrelated $\mathrm{scFv}$, ZW 88, and TGEV-negative serum were used as negative controls. Two serial dilutions of the scFv working stocks (1:20-1: 2560) were tested in triplicate. The results showed that TZZ 14, TZZ 19 and TZZ 43 significantly inhibit TGEV infection in a dose-dependent manner $(P<0.01)$ (Fig. 3A). Notably, TZZ 14 and TZZ 19 completely neutralized virus replication at a dilution of $1: 40$ and $1: 80$, respectively (Fig. 3B). No neutralizing activity was observed in the negative controls. Taken together, these results demonstrate the neutralizing activity of TZZ 14, TZZ 19 and TZZ 43 against TGEV in vitro.

\section{Identification of a viral protein recognized by scFv}

IFA results showed that the scFv antibody binds to TGEVinfected cells, but not uninfected cells, indicating that it specifically recognizes a TGEV protein (Fig. 4A). Since the S protein of coronaviruses is the major inducer of neutralizing antibodies, it was investigated whether scFv antibody binds to $S$ protein.

293T cells transfected with plasmid p3 $\times$ Flag-TGEV$\mathrm{S}$ were stained with TZZ 14 and TZZ 19, and specific fluorescence signals were observed in the cytoplasm. No distinct green signals were observed in cells transfected with $\mathrm{S}$ followed by incubation with TZZ 43 or ZW 88 (Fig. 4B). The reactivity of the selected scFv antibodies
Table 3 Enrichment of phages during each round of the biopanning process [31]

\begin{tabular}{lllll}
\hline $\begin{array}{l}\text { Round of } \\
\text { screening }\end{array}$ & $\begin{array}{l}\text { Coating antigen } \\
(\mu \mathrm{g} / \mathrm{mL})\end{array}$ & Input $(\mathrm{cfu} / \mathrm{mL})$ & Output $(\mathrm{cfu} / \mathrm{mL})$ & Output/Input $(\%)^{\mathrm{b}}$ \\
\hline $1^{\text {st }}$ & 20 & $1.32 \times 10^{12}$ & $5.75 \times 10^{4}$ & $4.36 \times 10^{-6}$ \\
$2^{\text {nd }}$ & 15 & $1.87 \times 10^{12}$ & $3.12 \times 10^{5}$ & $1.67 \times 10^{-5}$ \\
$3^{\text {rd }}$ & 10 & $1.43 \times 10^{12}$ & $2.25 \times 10^{6}$ & $1.57 \times 10^{-4}$ \\
$4^{\text {th }}$ & 5 & $1.12 \times 10^{12}$ & $2.78 \times 10^{7}$ & $2.48 \times 10^{-3}$ \\
\hline
\end{tabular}

${ }^{a}$ In each round of biopanning, the amount of coating antigen was reduced to select ScFvs with high affinity ${ }^{\mathrm{b}}$ Output/Input $(\%)=($ Output number $\times 100) /($ Input number $)$ 

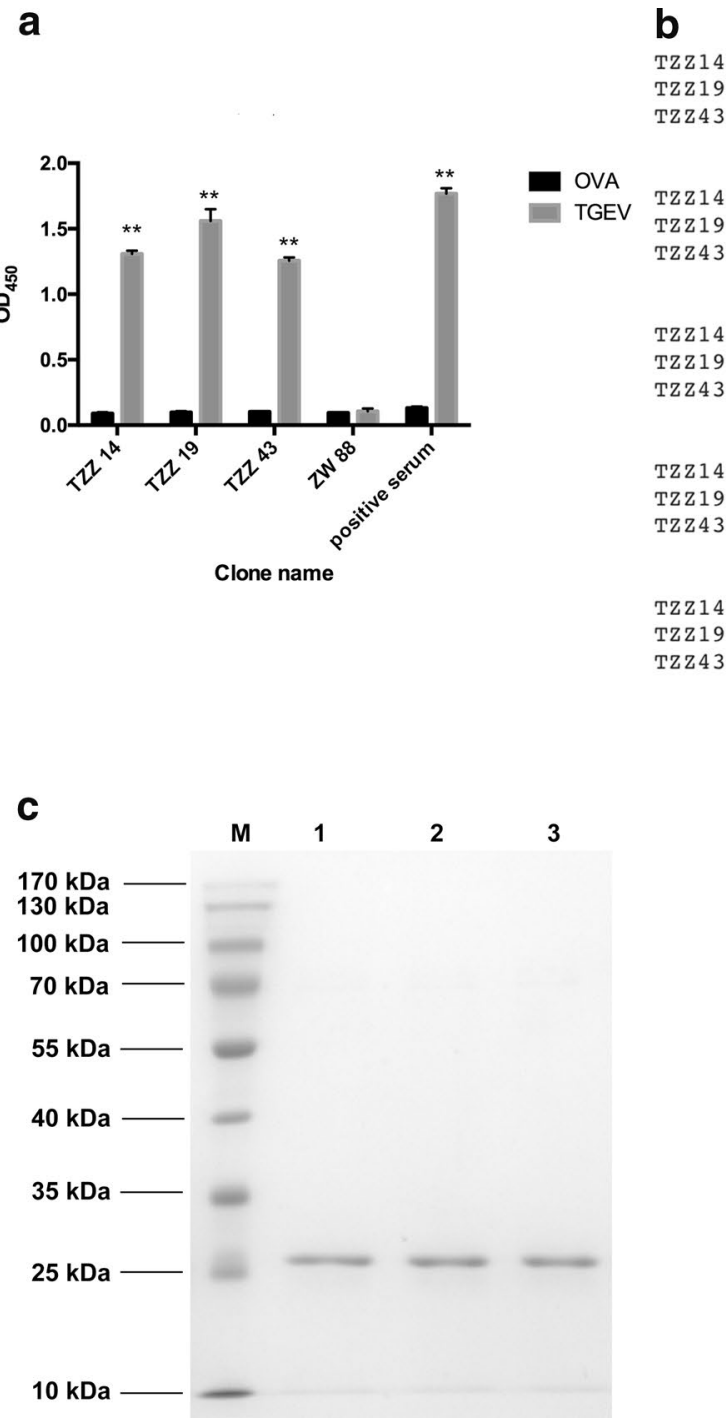

MAEEKLVESGGGLVQPGGSLRLSCVGSGFTFSSYEISWVRQAPGKGLEWLAVIYD--SGG MAEVKLVESGGGLVQPGGSLRLSCVGSGFTFSSYEISWVRQAPGKGLEWLARIYG--SGG MAEVKLVESGGGLVQPGGSLRLSCVGSGFTFGSTYITWVRQAPGKGLEWLAS IGSGSYSG ****************************** ITYYADSVKGRFTISRDNSQNTAYLQVNSLRTEDTARYYCAGCPRYGANCYTDPSYERDL LPYYADSVKGRFTISRDDSONTAYLOMTSLRTEDTARYYCAGSNYGSS-----TYPAMDL STYYADSVKGRFTISRDNSONTAYLQMNSLRTEDTARYYCARGGVTGS-----NYWDMDL ***************:********:.*************) WGPGVEVVVSSGGGGSGGGGSGGGGSOAVVTOEPA-MSVSLGGTVTLSCAFSSGS--VTS WGPGVEVVVSSGGGGSGGGGSGGGGSAIVLTQTPLSLSVSPGEPASISCRSSQSLLETDG WGPGVEVVVSSGGGGSGGGGSGGGGSELVMTQSPLSLSVSPGEPASISCRSSQSL-EEWG $\stackrel{* * * * * * * * * * * * * * * * * * * * * * * * *}{\longrightarrow} \quad *: * * * \quad: * * * * \quad .:: * * * \ldots \quad$. VH-FR4
SHWPSWYQQTPGQPPRQL IYKTNSRPTGVPSRFSGAISGNKATLTITGAQAEDEADYFCC KNSLNWYLQKAGQSPQRLIDQATNRDTGVPDRFSGNGSGTDFTLKISRVEAEDAGVYYCQ KGWLSWYOOKPSOSPRLL IYQATDRASGVPDRFCGSGSGPDFTLK IARVEADDAGVYYCO

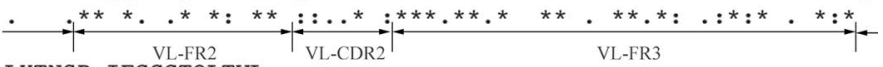
LYTNSP-IFGGGTQLTVL OFKEF-HGFGAGTKLEIK QYKEFPNGFGAGTKLDIK

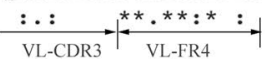

\section{d}

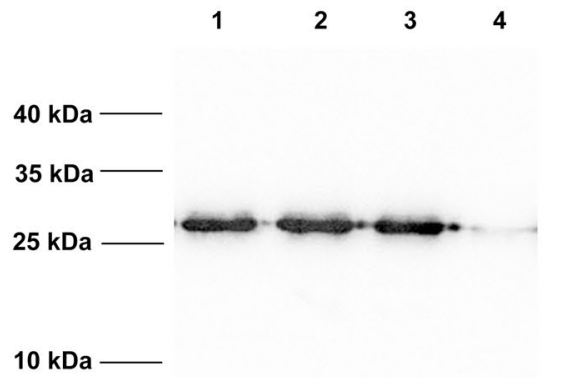

Fig. 2 Screening of $\mathrm{scFv}$ antibodies bound to TGEV. (A) Binding analysis of $\mathrm{scFv}$ antibodies to TGEV by phage ELISA. Fortyeight clones were randomly selected from the library and screened, and three clones (TZZ14, TZZ 19 and TZZ43) with relatively high binding affinity were identified. The data represent the means of three independent experiments; "**" represents a statistically significant difference $(p<0.01)$. Ovalbumin was served as a control antigen. Polyclonal serum against TGEV obtained from experimentally infected piglets and an unrelated $\mathrm{scFv}, \mathrm{ZW} 88$, were used as apositive and negative control, respectively. (B) Amino acid sequences of

three scFv antibodies. A glycine-rich linker $\left(\mathrm{G}_{4} \mathrm{~S}\right)_{3}$ that joins the $\mathrm{VH}$ fragment and VL is indicated. Sequences were aligned using Clustal Omega (http://www.ebi.ac.uk/Tools/msa/clustalo/). Dashes (-) indicate missing amino acids. (C) SDS-PAGE analysis of purified $\mathrm{scFv}$ antibodies against TGEV. Lane M, prestained protein ladder marker (Thermo Scientific); lane 1, purified scFv TZZ 14; lane 2, purified scFv TZZ 19; purified scFv TZZ 43. (D) Western blot analysis of purified $\mathrm{scFv}$ antibodies against TGEV. Lane 1, purified $\mathrm{scFv}$ TZZ 14; lane 2, purified $\mathrm{scFv}$ TZZ 19; lane 3, purified $\mathrm{scFv}$ TZZ 43; lane 4, E. coli BL21(DE3) transformed with pET-28a (+)

with the $\mathrm{S}$ protein was also evaluated using western blot (Fig. 4C). S protein was detected by TZZ 14, TZZ 19, and mouse anti-S monoclonal antibody, yielding a visible band at the predicted molecular weight $(\sim 160 \mathrm{kDa})$. S protein was not detected with TZZ 43 or ZW 88, and no band was observed on the NC membrane. These results indicate that TZZ 14 and TZZ 19 interact with the TGEV $S$ protein.

\section{Specificity of the scFv antibody}

To confirm the specificity of the purified scFv antibodies, an indirect ELISA was performed. The results showed that PZZ 14, PZZ 19 and PZZ 43 specifically bind to TGEV with no cross-reactivity with other available porcine pathogens (including PEDV, PRRSV, PCV2), suggesting that $\mathrm{scFv}$ antibodies could be used in the diagnosis of TGEV infection (Fig. 5). 
Fig. 3 Neutralizing activity of purified $\mathrm{scFv}$ antibodies. (A) The neutralization activity was measured by plaque reduction neutralization (PRN) assay on ST cells. Diluted scFv antibody was incubated with TGEV; this was followed by infection of ST cells. The scFv antibodies showed no affinity for TGEV and were used as a negative control. (B) The reduction in virus titer corresponded to changing $\mathrm{scFv}$ antibody concentration. scFv TZZ 14, TZZ 19 and TZZ 43 inhibited TGEV infection. An unrelated scFv ZW 88 and TGEV-negative porcine serum were used as a negative control. Inhibition rates (in percent) were calculated as follows: [1 - (plaques in treated wells/plaques in control $\mathrm{scFv}$ $\mathrm{ZW} 88$ wells) $] \times 100$. The means and standard deviations of the three experiments are shown a

TZZ 14
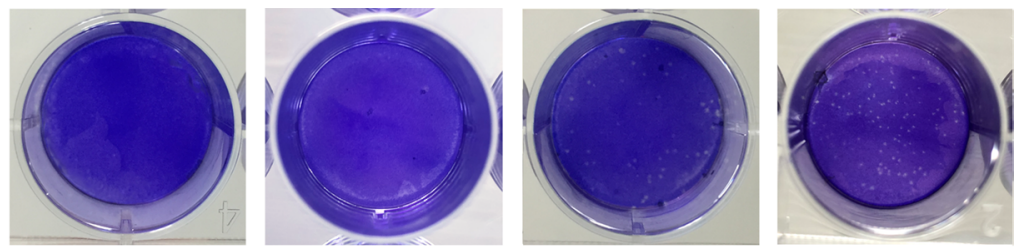

TZZ 19
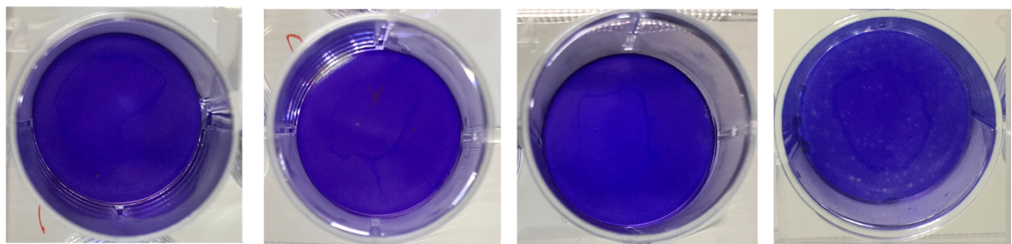

TZZ 43
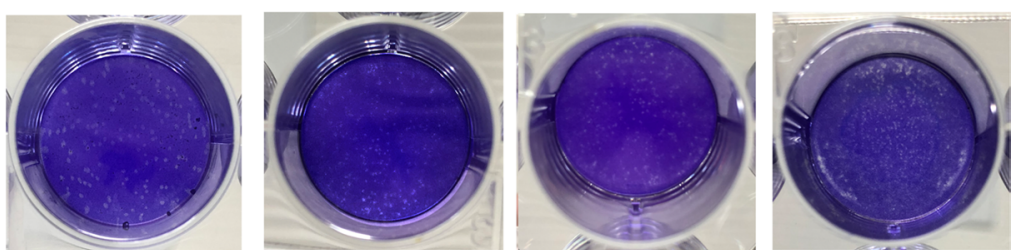

ZW 88
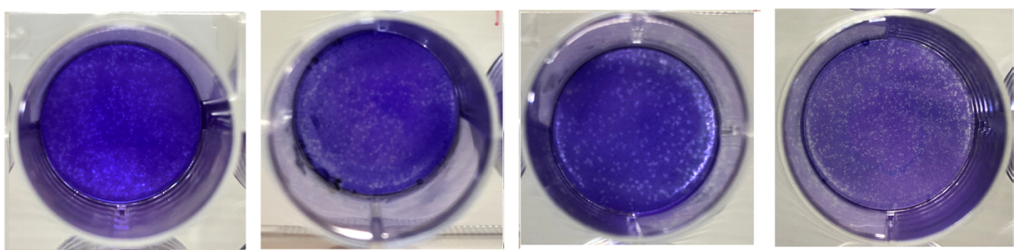

Negative

serum
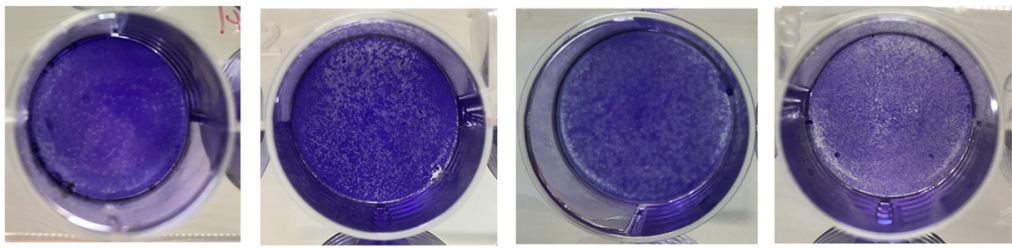

Mock
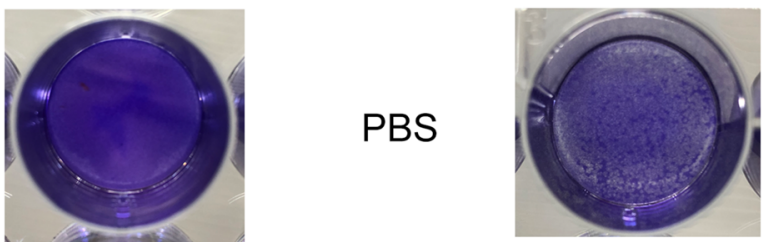

PBS

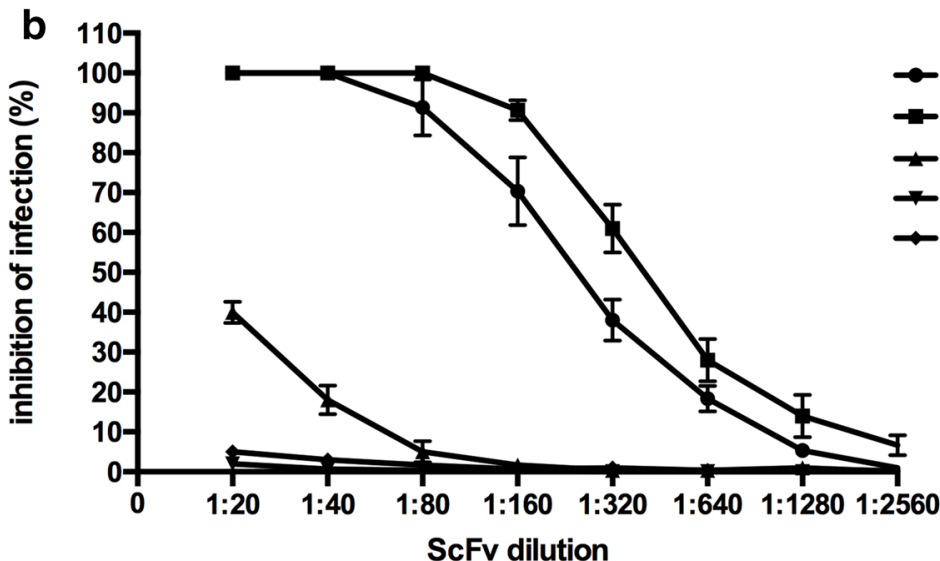




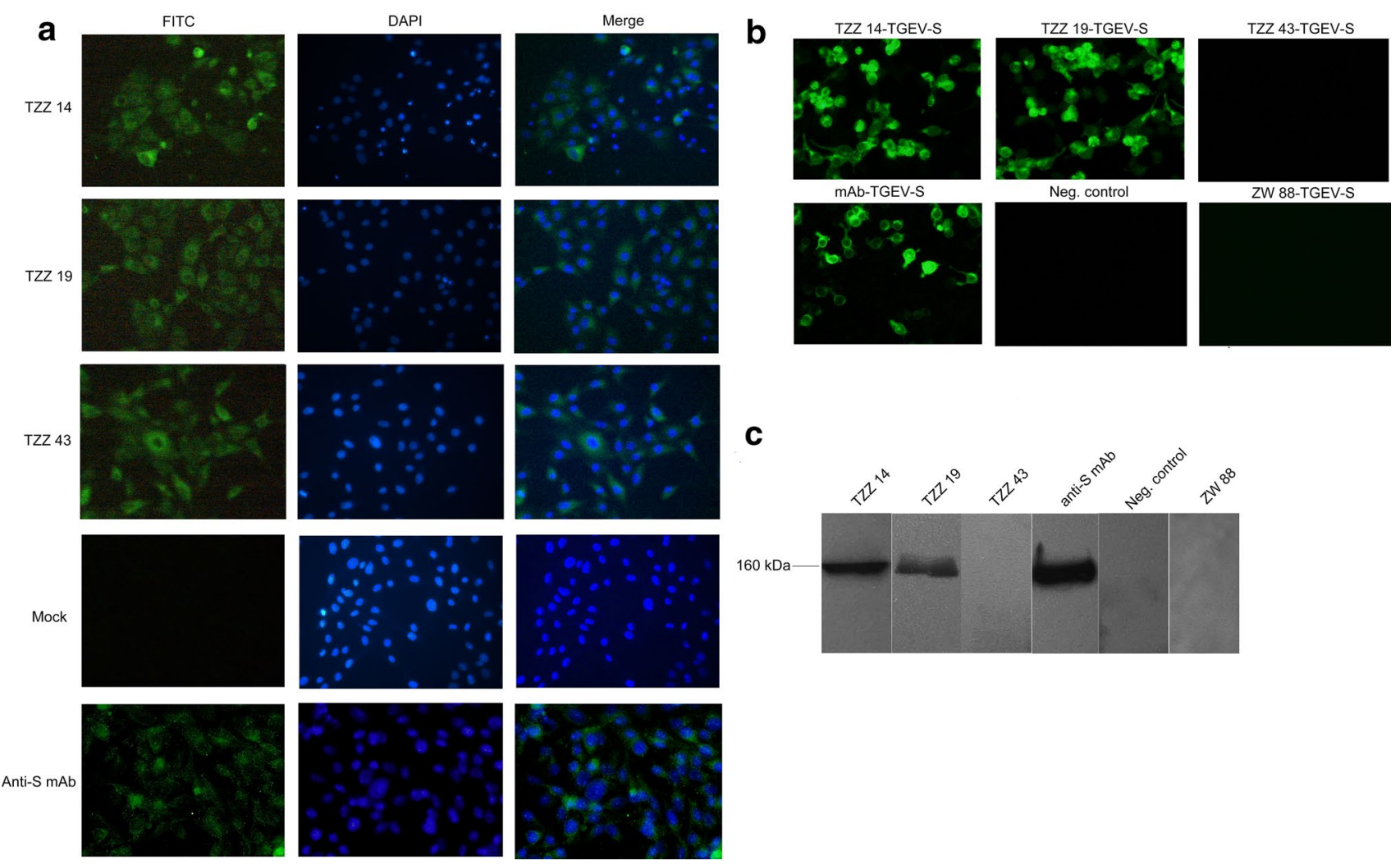

Fig. 4 Purified $\mathrm{scFv}$ antibodies bound to the TGEV $\mathrm{S}$ protein. (A) All three scFv antibodies bound specifically to TGEV-infected cells. ST cells were infected with TGEV SHXB strains and incubated with purified $\mathrm{scFv}$ or anti-TGEV spike (S) protein monoclonal antibody followed by FITC-conjugated secondary antibody. The nuclei were counterstained with 4', 6'-diamidino-2-phenylindole (DAPI). Cells that were not infected with TGEV were used as a negative control and examined under a fluorescence microscope. (B) Identification of the viral protein recognized by the scFv antibody. 293T cells were transfected with recombinant plasmid pCDNA3.1(+)-S and incubated with $\mathrm{scFv}$ antibody, an unrelated $\mathrm{scFv}$, ZW 88 , or anti-TGEV spike

\section{Discussion}

TGEV infection is characterized by severe diarrhea, vomiting and dehydration, with high morbidity and mortality in suckling piglets (especially in piglets younger than two weeks of age). This can cause significant economic losses on affected farms [3]. In neonatal piglets, the main mechanism of protection is mediated by lactogenic immunity. Sows are vaccinated with inactivated or attenuated vaccine in order to induce the production of secretary IgA in colostrum and milk. The neonatal piglets are passively protected from TGEV when they ingest colostrum and/or milk with high titers of anti-TGEV secretory IgA antibodies [15]. Sows inoculated with inactivated vaccine do not generate the required local immune response in the small intestine and the replication of the attenuated viruses is limited, resulting in an inadequate immune response. Piglets cannot overcome
(S) protein monoclonal antibody, followed by staining with FITCconjugated secondary antibody. The cells were examined under a fluorescence microscope. Cells transfected with p3 $\times$ FLAG-CMV-14 followed by staining with mouse anti-TGEV $\mathrm{S}$ monoclonal antibody were used as an additional negative control. (C) The binding of scFv antibody to viral proteins was measured by Western blot analysis. The membrane containing the proteins was incubated with purified $\mathrm{scFv}$, an unrelated scFv, ZW 88, or anti-TGEV spike (S) protein monoclonal antibody. Cells transfected with $3 \times$ FLAG-CMV-14 followed by staining with mouse anti-TGEV $\mathrm{S}$ monoclonal antibody were used as an additional negative control

infection unless adequate maternal antibodies are acquired. Passive immunization by oral administration of specific antibodies or antibody derivatives represents an attractive approach against TGEV infection. Egg yolk antibodies (IgY) against TGEV that are administrated orally to suckling piglets show a prophylactic effect on the piglets. Lee $e t$ $a l$. demonstrated that oral administration of antibodies can protect piglets from diarrhea, which indicates that antibody administration is an alternative way of controlling TGEV infection [34]. Besides traditional polyclonal serum and monoclonal antibodies, oral administration of recombinant antibodies can also protect the host from diarrhea. Garaicoechea et al. demonstrated that mice that were inoculated orally with single-chain antibody fragments (VHH) against the inner capsid protein VP6 of rotavirus (RV) protected mice from rotavirus diarrhea [35]. This study offers promising alternative strategies to prevent $\mathrm{RV}$-induced diarrhea and 


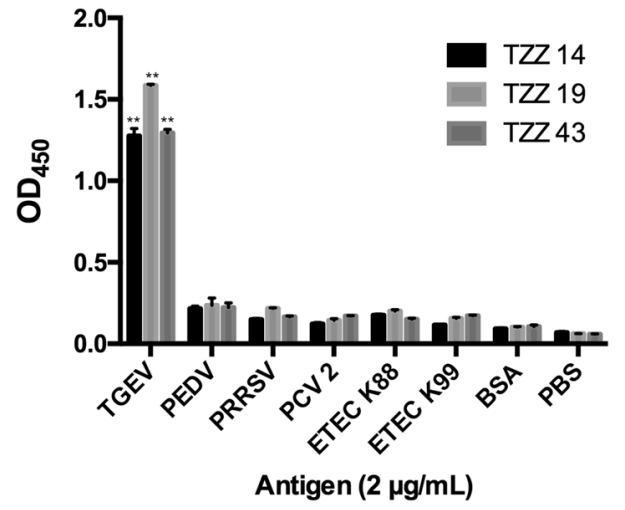

Fig. 5 Binding specificity of purified $\mathrm{scFv}$ antibodies. Three $\mathrm{scFv}$ antibodies were evaluated for cross-reactivity against the following swine pathogens: transmissible gastroenteritis virus (TGEV), porcine epidemic diarrhea virus (PEDV), porcine respiratory syndrome virus (PRRSV), porcine circovirus type 2 (PCV2), ETEC enterotoxigenic Escherichia coli (ETEC) K88, and ETEC K99. BSA was used as a negative control. The data represent the means from three independent experiments. “**”" indicates a statistically significant difference $(p$ $<0.01)$

suggests that our selected scFv antibodies may be used as a novel therapeutic reagent to control porcine transmissible gastroenteritis in suckling piglets.

Phage display technology dates back 30 years to the discovery that foreign DNA fragments can be fused to the gene encoding the pIII coat protein of a nonlytic filamentous phage and expressed as a fusion protein on the virion surface [36]. A few years later, McCafferty et al. first reported that scFv antibodies can be displayed on the surface of the phage through phage display technology and that $\mathrm{scFv}$ antibodies can be obtained after biopanning [37]. This technique for the production of $\mathrm{scFv}$ antibodies has several advantages: rapid culture of phage clones, easy handling and detection of secreted antibodies, genetic stability, and lower production costs compared with monoclonal antibodies [38, 39]. Lika et al. first attempted to construct a porcine phage library by analyzing sequence data in the IMGT database [40]. These authors reported that information on the kappa and lambda chain repertoire is scant and that some of the kappa/lambda chains might not be recovered from the sites of the transcripts of porcine spleen [40]. The porcine scFv antibody library is incomplete, and further research is required. In this study, we constructed a porcine $\mathrm{scFv}$ antibody library against TGEV. The library size was large enough to select specific $\mathrm{scFv}$ antibodies despite being smaller than the recommended size $\left(6 \times 10^{8} \mathrm{pfu} / \mathrm{mL}\right)$. To our knowledge, this is the first study using a porcine antibody phage library to select $\mathrm{scFv}$ antibodies against TGEV.

The $\mathrm{scFv}$ is a small, genetically engineered recombinant antibody in which the VH and VL chain of the antibody are connected by a flexible peptide linker. The $\mathrm{scFv}$ has considerable potential for use in receptor blockades, pathogen neutralization and therapeutic antigen targeting in vivo $[41,42]$. In this study, phages expressing $\mathrm{scFv}$ antibodies were selected after four rounds of biopanning. TZZ 14, TZZ 19 and TZZ 43 were chosen because of their high binding affinity to TGEV antigen. The DNA sequences of the scFv antibodies were analyzed and their amino acid sequences were deduced. Our results showed that sequences of these $\mathrm{scFv}$ antibodies share similarities in the FRs and that their CDRs are highly variable, especially the CDR3 of $\mathrm{VH}$ and VL. Since CDRs contribute to the specificity for binding to a specific epitope, a difference in the diversity of CDR3 in the $\mathrm{VL}$ and $\mathrm{VH}$ domains reflects differences in antigen binding. We did not determine the affinity of this interaction, but we infer from the phage ELISA and sequence analysis that these two antibodies were variable. Previous studies indicate that $\mathrm{scFv}$ antibodies are able to neutralize various viral infections, including influenza A virus (H5N1 subtype), human immunodeficiency virus 1 , respiratory syncytial virus, rabies virus, and infectious bronchitis virus [43-47]. Notably, most $\mathrm{scFv}$ antibodies can target viral surface glycoproteins, which in turn play a role in blocking virus adherence to receptors of host cells. These scFv antibodies with high affinity to TGEV antigen were further analyzed using a neutralization assay. Our results indicate that three scFv antibodies have a neutralization effect on TGEV infection.

The $\mathrm{S}$ protein of the porcine coronavirus TGEV is a large surface glycoprotein. It is responsible for inducing neutralizing antibodies, and it also affects viral binding to host cells before invasion, and thus pathogenicity $[6,48]$. The neutralization assay indicated that three scFv antibodies exert neutralization activity. IFA results showed that ST cells transfected with $\mathrm{p} 3 \mathrm{XFLAG-TGEV-S} \mathrm{was} \mathrm{stained} \mathrm{by}$ TZZ 14 and TZZ 19. The exact epitope recognized by the $\mathrm{scFv}$ antibodies is still unknown, and current work is ongoing to map the epitopes recognized by each scFv. IFA and western blot results showed that scFv TZZ 43 do not bind to $\mathrm{S}$ protein-transfected cells. Some studies have shown that the nucleocapsid $(\mathrm{N})$ protein of TGEV is also an inducer of neutralizing antibodies, and swine vaccinated with the $\mathrm{N}$ protein produce a mucosal immune responses against TGEV [49, 50]. Thus, TZZ 43 might neutralize virus infection through interacting with another TGEV viral protein (e.g. the $\mathrm{N}$ protein).

In conclusion, a porcine $\mathrm{scFv}$ antibody phage display library was successfully constructed. scFv antibodies were selected from the antibody library by several rounds of biopanning using purified TGEV as the antigen. The scFv antibody was expressed in $E$. coli in a soluble form. PRN assay results showed that TZZ 14, TZZ 19 and TZZ 43 could neutralize virus replication. IFA results showed that TZZ 14, TZZ 19 and TZZ 43 bind to TGEV -infected cells and TZZ 14 and TZZ 19 bind to TGEV S protein-transfected 
cells. Our research lays the foundation for further $\mathrm{scFv}$ development.

Acknowledgements This work was financially supported by the Key Project of Science and Technology for Agriculture of Shanghai (Hu Nong Ke Gong Zi (2015) no. 1-8).

\section{Compliance with ethical standards}

Conflict of interest The authors declare that they have no conflict of interest.

Ethical approval The animal experiment was performed in accordance with the recommendations in the Guidelines for the Use of Laboratory Animals provided by the Science and Technology Commission of Shanghai Municipality (STCSM). The protocol was approved by the ethics committee of the Shanghai JiaoTong University, School of Agriculture and Biology.

\section{References}

1. Masters PS (2006) The molecular biology of coronaviruses. Adv Virus Res 66:193-292. https://doi.org/10.1016/s0065 -3527(06)66005-3

2. Jones T, Pritchard G, Paton D (1997) Transmissible gastroenteritis of pigs. Vet Rec 141:427-428

3. Schwegmann-Wessels C, Herrler G (2006) Transmissible gastroenteritis virus infection: a vanishing specter. Dtsch Tierarztl Wochenschr 113:157-159

4. Spaan W, Cavanagh D, Horzinek MC (1988) Coronaviruses: structure and genome expression. J Gen Virol 69(Pt 12):2939-2952. https://doi.org/10.1099/0022-1317-69-12-2939

5. Laude H, Van Reeth K, Pensaert M (1993) Porcine respiratory coronavirus: molecular features and virus-host interactions. Vet Res 24:125-150

6. Krempl C, Schultze B, Laude H, Herrler G (1997) Point mutations in the $\mathrm{S}$ protein connect the sialic acid binding activity with the enteropathogenicity of transmissible gastroenteritis coronavirus. J Virol 71:3285-3287

7. Delmas B, Gelfi J, L'Haridon R, Vogel LK, Sjostrom H, Noren O, Laude H (1992) Aminopeptidase $\mathrm{N}$ is a major receptor for the entero-pathogenic coronavirus TGEV. Nature 357:417-420. https ://doi.org/10.1038/357417a0

8. Delmas B, Rasschaert D, Godet M, Gelfi J, Laude H (1990) Four major antigenic sites of the coronavirus transmissible gastroenteritis virus are located on the amino-terminal half of spike glycoprotein S. J Gen Virol 71(Pt 6):1313-1323. https://doi. org/10.1099/0022-1317-71-6-1313

9. Reguera J, Ordono D, Santiago C, Enjuanes L, Casasnovas JM (2011) Antigenic modules in the N-terminal S1 region of the transmissible gastroenteritis virus spike protein. J Gen Virol 92:1117-1126

10. Enjuanes L, Sune C, Gebauer F, Smerdou C, Camacho A, Anton IM, Gonzalez S, Talamillo A, Mendez A, Ballesteros ML et al (1992) Antigen selection and presentation to protect against transmissible gastroenteritis coronavirus. Vet Microbiol 33:249-262

11. Meng F, Ren Y, Suo S, Sun X, Li X, Li P, Yang W, Li G, Li L, Schwegmann-Wessels C, Herrler G, Ren X (2013) Evaluation on the efficacy and immunogenicity of recombinant DNA plasmids expressing spike genes from porcine transmissible gastroenteritis virus and porcine epidemic diarrhea virus. PLoS One 8:e57468
12. Gerdts V, Zakhartchouk A (2017) Vaccines for porcine epidemic diarrhea virus and other swine coronaviruses. Vet Microbiol 206:45-51. https://doi.org/10.1016/j.vetmic.2016.11.029

13. Langel SN, Paim FC, Lager KM, Vlasova AN, Saif LJ (2016) Lactogenic immunity and vaccines for porcine epidemic diarrhea virus (PEDV): historical and current concepts. Virus Res 226:93-107. https://doi.org/10.1016/j.virusres.2016.05.016

14. Bohl EH, Gupta RK, Olquin MV, Saif LJ (1972) Antibody responses in serum, colostrum, and milk of swine after infection or vaccination with transmissible gastroenteritis virus. Infect Immun 6:289-301

15. Wesley RD, Woods RD (2001) Partial passive protection with two monoclonal antibodies and frequency of feeding of hyperimmune anti-transmissible gastroenteritis virus (TGEV) serum for protection of three-day-old piglets from a TGEV challenge infection. J Vet Diagn Investig 13:290-296. https://doi. org/10.1177/104063870101300402

16. Bestagno M, Sola I, Dallegno E, Sabella P, Poggianella M, Plana-Duran J, Enjuanes L, Burrone OR (2007) Recombinant dimeric small immunoproteins neutralize transmissible gastroenteritis virus infectivity efficiently in vitro and confer passive immunity in vivo. J Gen Virol 88:187-195. https://doi. org/10.1099/vir.0.82192-0

17. Unkauf T, Miethe S, Fuhner V, Schirrmann T, Frenzel A, Hust $M$ (2016) Generation of recombinant antibodies against toxins and viruses by phage display for diagnostics and therapy. Adv Exp Med Biol 917:55-76. https://doi.org/10.1007/978-3-31932805-8_4

18. Bustamante-Cordova L, Melgoza-Gonzalez EA, Hernandez J (2018) Recombinant antibodies in veterinary medicine: an update. Front Vet Sci 5:175

19. Golchin M, Aitken R (2008) Isolation by phage display of recombinant antibodies able to block adherence of Escherichia coli mediated by the K99 colonisation factor. Vet Immunol Immunopathol 121:321-331. https://doi.org/10.1016/j.vetim m.2007.10.005

20. Chai Z, Fu F, Jiang F, Tian H, Wang Z, Zheng N, Zhang X, Wang X, Li X (2014) Development of a neutralizing mousepig chimeric antibody with therapeutic potential against Haemophilus parasuis in Pichia pastoris. FEMS Microbiol Lett 354:85-91. https://doi.org/10.1111/1574-6968.12437

21. Corti D, Voss J, Gamblin SJ, Codoni G, Macagno A, Jarrossay D, Vachieri SG, Pinna D, Minola A, Vanzetta F, Silacci C, Fernandez-Rodriguez BM, Agatic G, Bianchi S, GiacchettoSasselli I, Calder L, Sallusto F, Collins P, Haire LF, Temperton N, Langedijk JP, Skehel JJ, Lanzavecchia A (2011) A neutralizing antibody selected from plasma cells that binds to group 1 and group 2 influenza A hemagglutinins. Science 333:850-856. https://doi.org/10.1126/science.1205669

22. Weisser NE, Hall JC (2009) Applications of single-chain variable fragment antibodies in therapeutics and diagnostics. Biotechnol Adv 27:502-520. https://doi.org/10.1016/j.biotechadv .2009 .04 .004

23. Schofield DJ, Pope AR, Clementel V, Buckell J, Chapple S, Clarke KF, Conquer JS, Crofts AM, Crowther SR, Dyson MR, Flack G, Griffin GJ, Hooks Y, Howat WJ, Kolb-Kokocinski A, Kunze S, Martin CD, Maslen GL, Mitchell JN, O’Sullivan M, Perera RL, Roake W, Shadbolt SP, Vincent KJ, Warford A, Wilson WE, Xie J, Young JL, McCafferty J (2007) Application of phage display to high throughput antibody generation and characterization. Genome Biol 8:R254

24. Yokota T, Milenic DE, Whitlow M, Schlom J (1992) Rapid tumor penetration of a single-chain $\mathrm{Fv}$ and comparison with other immunoglobulin forms. Cancer Res 52:3402-3408 
25. Better M, Chang CP, Robinson RR, Horwitz AH (1988) Escherichia coli secretion of an active chimeric antibody fragment. Science 240:1041-1043

26. Liu H, Wang Y, Duan H, Zhang A, Liang C, Gao J, Zhang C, Huang B, Li Q, Li N, Xiao S, Zhou EM (2015) An intracellularly expressed Nsp9-specific nanobody in MARC-145 cells inhibits porcine reproductive and respiratory syndrome virus replication. Vet Microbiol 181:252-260. https://doi.org/10.1016/j.vetmi c. 2015.10.021

27. Pyo HM, Kim IJ, Kim SH, Kim HS, Cho SD, Cho IS, Hyun BH (2009) Escherichia coli expressing single-chain Fv on the cell surface as a potential prophylactic of porcine epidemic diarrhea virus. Vaccine 27:2030-2036. https://doi.org/10.1016/j.vacci ne.2009.01.130

28. Harmsen MM, Fijten HP, Engel B, Dekker A, Eble PL (2009) Passive immunization with llama single-domain antibody fragments reduces foot-and-mouth disease transmission between pigs. Vaccine 27:1904-1911. https://doi.org/10.1016/j.vaccine.2009.01.110

29. Krempl C, Herrler G (2001) Sialic acid binding activity of transmissible gastroenteritis coronavirus affects sedimentation behavior of virions and solubilized glycoproteins. J Virol 75:844-849

30. Wang M, Zhang Y, Li B, Zhu J (2015) Construction of scFv that bind both fibronectin-binding protein $\mathrm{A}$ and clumping factor $\mathrm{A}$ of Stapylococcus aureus. Res Vet Sci 100:109-114. https://doi. org/10.1016/j.rvsc.2015.02.012

31. Lee CM, Iorno N, Sierro F, Christ D (2007) Selection of human antibody fragments by phage display. Nat Protoc 2:3001-3008. https://doi.org/10.1038/nprot.2007.448

32. Wang M, Zhang Y, Zhu J (2016) Anti-Staphylococcus aureus single-chain variable region fragments provide protection against mastitis in mice. Appl Microbiol Biotechnol 100:2153-2162. https ://doi.org/10.1007/s00253-015-7045-8

33. Hofmann M, Wyler R (1989) Quantitation, biological and physicochemical properties of cell culture-adapted porcine epidemic diarrhea coronavirus (PEDV). Vet Microbiol 20:131-142

34. Lee DH, Jeon YS, Park CK, Kim S, Lee DS, Lee C (2015) Immunoprophylactic effect of chicken egg yolk antibody $(\operatorname{IgY})$ against a recombinant $\mathrm{S} 1$ domain of the porcine epidemic diarrhea virus spike protein in piglets. Arch Virol 160:2197-2207. https://doi. org/10.1007/s00705-015-2494-z

35. Garaicoechea L, Olichon A, Marcoppido G, Wigdorovitz A, Mozgovoj M, Saif L, Surrey T, Parreno V (2008) Llama-derived single-chain antibody fragments directed to rotavirus VP6 protein possess broad neutralizing activity in vitro and confer protection against diarrhea in mice. J Virol 82:9753-9764

36. Smith GP (1985) Filamentous fusion phage: novel expression vectors that display cloned antigens on the virion surface. Science 228:1315-1317

37. McCafferty J, Griffiths AD, Winter G, Chiswell DJ (1990) Phage antibodies: filamentous phage displaying antibody variable domains. Nature 348:552-554. https://doi.org/10.1038/348552a0

38. Wu CC, Lin EH, Lee YC, Tai CJ, Kuo TH, Wang HE, Luo TY, Fu YK, Chen HJ, Sun MD, Wu CH, Wu CW, Leu SJ, Deng WP (2010) Identification of a new peptide for fibrosarcoma tumor targeting and imaging in vivo. J Biomed Biotechnol 2010:167045

39. Foy BD, Killeen GF, Frohn RH, Impoinvil D, Williams A, Beier JC (2002) Characterization of a unique human single-chain antibody isolated by phage-display selection on membrane-bound mosquito midgut antigens. J Immunol Methods 261:73-83

40. Li F, Aitken R (2004) Cloning of porcine scFv antibodies by phage display and expression in Escherichia coli. Vet Immunol Immunopathol 97:39-51

41. Haidaris CG, Malone J, Sherrill LA, Bliss JM, Gaspari AA, Insel RA, Sullivan MA (2001) Recombinant human antibody single chain variable fragments reactive with Candida albicans surface antigens. J Immunol Methods 257:185-202

42. Pansri P, Jaruseranee N, Rangnoi K, Kristensen P, Yamabhai M (2009) A compact phage display human scFv library for selection of antibodies to a wide variety of antigens. BMC Biotechnol 9:6

43. Yang J, Yoshida R, Kariya Y, Zhang X, Hashiguchi S, Nakashima T, Suda Y, Takada A, Ito Y, Sugimura K (2010) Characterization of human single-chain antibodies against highly pathogenic avian influenza H5N1 viruses: mimotope and neutralizing activity. J Biochem 148:507-515. https://doi.org/10.1093/jb/mvq084

44. Khan L, Kumar R, Thiruvengadam R, Parray HA, Makhdoomi MA, Kumar S, Aggarwal H, Mohata M, Hussain AW, Das R, Varadarajan R, Bhattacharya J, Vajpayee M, Murugavel KG, Solomon S, Sinha S, Luthra K (2017) Cross-neutralizing anti-HIV-1 human single chain variable fragments(scFvs) against CD4 binding site and N332 glycan identified from a recombinant phage library. Sci Rep 7:45163

45. Guirakhoo F, Catalan J, Monath T, Weltzin R (1996) Cloning, expression and functional activities of a single chain antibody fragment directed to fusion protein of respiratory syncytial virus. Immunotechnology 2:219-228

46. Muller BH, Lafay F, Demangel C, Perrin P, Tordo N, Flamand A, Lafaye P, Guesdon JL (1997) Phage-displayed and soluble mouse $\mathrm{scFv}$ fragments neutralize rabies virus. J Virol Methods 67:221-233

47. Lin Y, Li B, Ye J, Wang M, Wang J, Zhang Y, Zhu J (2015) Neutralization analysis of a chicken single-chain variable fragment derived from an immune antibody library against infectious bronchitis virus. Viral Immunol 28:397-404. https://doi.org/10.1089/ vim.2014.0104

48. Jacobs L, van der Zeijst BA, Horzinek MC (1986) Characterization and translation of transmissible gastroenteritis virus mRNAs. J Virol 57:1010-1015

49. Sestak K, Meister RK, Hayes JR, Kim L, Lewis PA, Myers G, Saif LJ (1999) Active immunity and T-cell populations in pigs intraperitoneally inoculated with baculovirus-expressed transmissible gastroenteritis virus structural proteins. Vet Immunol Immunopathol 70:203-221

50. Zhang D, Huang X, Zhang X, Cao S, Wen X, Wen Y, Wu R, Liang $\mathrm{E}$ (2016) Construction of an oral vaccine for transmissible gastroenteritis virus based on the TGEV N gene expressed in an attenuated Salmonella typhimurium vector. J Virol Methods 227:6-13. https://doi.org/10.1016/j.jviromet.2015.08.011

Publisher's Note Springer Nature remains neutral with regard to jurisdictional claims in published maps and institutional affiliations. 